\title{
Counseling of Female Veterans About Risks of Medication- Induced Birth Defects
}

\author{
Eleanor Bimla Schwarz, MD, MS ${ }^{7,8}$, Kristin Mattocks, PhD, MPH 6,7 , Cynthia Brandt, MD, MPH, \\ Sonya Borrero, $M D, M S^{1,3,8}$, Laurie C. Zephyrin, $M D, M P H^{4}$, Harini Bathulapalli, $\mathrm{MPH}^{2}$, and \\ Sally Haskell, $M D^{4,5}$
}

\begin{abstract}
${ }^{1}$ Center for Research on Health Care, University of Pittsburgh School of Medicine, Pittsburgh, PA, USA; ${ }^{2}$ Yale University School of Medicine, New Haven, CT, USA; ${ }^{3}$ Center for Health Equity Research and Promotion, VA Pittsburgh, Pittsburgh, PA, USA; ${ }^{4}$ Women Health Services, VA Central Office, Washington, DC, USA; ${ }^{5}$ VA Connecticut Healthcare System, West Haven, CT, USA; ${ }^{6}$ VA Central Western Massachusetts Healthcare System, Leeds, MA, USA; ${ }^{7}$ University of Massachusetts Medical School, Worcester, MA, USA; ${ }^{8}$ Department of Medicine, University of Pittsburgh, Pittsburgh, PA, USA.
\end{abstract}

\begin{abstract}
BACKGROUND: Medications that may increase risk of birth defects if used during pregnancy or immediately preconception are dispensed to approximately half of female Veterans who fill prescriptions at a VA pharmacy. OBJECTIVE: To assess receipt of counseling about risk of medication-induced birth defects among female Veterans of reproductive age and to examine Veterans' confidence that their healthcare provider would counsel them about teratogenic risks.
\end{abstract}

DESIGN AND PARTICIPANTS: Cross-sectional analysis of data provided by 286 female Veterans of Operation Iraqi Freedom and/or Operation Enduring Freedom who completed a mailed survey between July 2008 and October 2010.

MAIN MEASURES: We examined associations between demographic, reproductive, and health service utilization variables and female Veterans' receipt of counseling and confidence that they would receive such counseling.

KEY RESULTS: The response rate was $11 \%$; the large majority ( $89 \%)$ of responding female Veterans reported use of a prescription medication in the last 12 months. Most (90\%) of the 286 female Veterans who reported medication use were confident that they would be told by their healthcare provider if a medication might cause a birth defect. However, only $24 \%$ of women who received prescription medications reported they had been warned of teratogenic risks. Female Veterans who used medications that are known to be teratogenic were not more likely than women using other medications to report having been warned about risks of medicationinduced birth defects, and fewer were confident that their health care providers would provide teratogenic risk counseling when needed.

CONCLUSIONS: Female Veterans may not receive appropriate counseling when medications that can cause birth defects are prescribed.
KEY WORDS: preconception care; contraceptive counseling; birth defects; veterans; women's health.

J Gen Intern Med 28(Suppl 2):S598-603

DOI: $10.1007 /$ s11606-012-2240-0

(C) Society of General Internal Medicine 2012

$B$ irth defects are a leading cause of infant mortality. ${ }^{1}$ Each year, an estimated 120,000 US infants suffer from birth defects ${ }^{2}$ and require billions of dollars in health care. ${ }^{3}$ Although the causes of most birth defects are unknown, some medications have been identified as increasing risk of birth defects. In the United States, women of reproductive age receive an estimated 12 million prescriptions for potentially teratogenic medications each year. ${ }^{4}$

While the US Department of Veterans Affairs (VA) has historically served a predominantly male population, the number of female Veterans enrolled in the VA health care system has been growing rapidly. Between 1999 and 2006, the number of women served by the Veterans Health Administration (VHA) more than doubled. Currently, there are approximately 337,000 female Veterans using VHA care on an annual basis, and the number of women in the military continues to increase. As two thirds of female Veterans returning from Operation Enduring Freedom(OEF) and Operation Iraqi Freedom (OIF) were under 30 years of age, the VA Healthcare system is caring for a growing number of women of childbearing age. ${ }^{5}$

Given the higher burden of comorbid conditions in female Veterans compared to women seen in other settings, ${ }^{6}$ female Veterans are more likely to be dispensed potentially teratogenic medications. It is estimated that half of fertile female Veterans who receive prescriptions from a VA pharmacy fill a prescription for a potentially teratogenic medication each year. ${ }^{7}$ For example, each year, VA pharmacies dispense potentially teratogenic psychiatric medications to over 20,000 female Veterans of reproductive age, a statin is dispensed to close to 9,000 female Veterans, 
and an angiotensin converting enzyme (ACE) inhibitor or "angiotensin receptor blockers" (ARB) is dispensed to over 6,000 female Veterans. $^{7}$

Nationally, it is estimated that fewer than $50 \%$ of women using potentially teratogenic medications receive contraceptive counseling during ambulatory care visits. ${ }^{4,6}$ As a result, approximately $6 \%$ of US pregnancies are exposed to potentially teratogenic medications. ${ }^{8,9}$ As little is known about how VA clinicians counsel their patients about the risks of medication-induced birth defects, the goal of this study is to evaluate the prevalence of receipt of counseling about teratogenic risks among female Veterans, and to assess female Veterans' confidence that their healthcare providers would tell them if a medication they were taking might cause a birth defect.

\section{METHODS}

The data used for this study was collected as part of a larger research study, the Women Veterans Cohort Study (WVCS). ${ }^{10}$ WVCS is a two-phase longitudinal study examining healthcare utilization, health outcomes, and costs of care among a cohort of OEF/OIF male and female veterans in VA care. The sampling frame for the overall study is the OEF/OIF roster, provided to the VA by the Department of Defense Manpower Data Center's (DMDC) Contingency Tracking System. The $\mathrm{OEF} / \mathrm{OIF}$ roster is a database of veterans who separated from $\mathrm{OEF} / \mathrm{OIF}$ military service and enrolled in VA healthcare between October 1, 2001 and April 30, 2010 ( $N=749,036$ of whom 88,166 are women). Roster information includes veterans' sex, race, date of birth, deployment dates, armed forces branch (Army, Navy, Air Force, Marines, or Coast Guard) and component (National Guard, Reserve or active duty).

This paper utilizes data from the second phase (prospective survey component) of WVCS. OEF/OIF veterans who were enrolled for care in the New England Region or Indiana were invited to participate in this prospective study. These regions were selected as a matter of convenience, as funding constraints precluded the study of more regions. Thus, letters were sent to 3,251 female OEF/OIF veterans. Veterans expressing interest in the study, that is those who "opted in," either met with or called the research coordinator, who provided a detailed description of the study, which would involve completion of three surveys over the course of 2 years, and screened for eligibility criteria including the ability to speak and read English, and participation in OEF or OIF. Those who agreed to participate were given an appointment at which they provided signed informed consent and completed the baseline survey, which was the source of data for these analyses. This survey was developed and pilottested by the WVCS investigators. Between July 2008 and October 2011, baseline surveys were completed by $11 \%$ of female Veterans who were invited to participate $(n=365)$. For the purposes of this analysis, we excluded Veterans over
50 years of age $(n=27)$ and those using post-menopausal hormone therapy $(n=16)$, producing a sample of 322 female premenopausal Veterans. For analyses regarding receipt of counseling about risks of medication-induced birth defects, we further excluded 36 women who had not used prescription medication in the last 12 months.

All medication data was self-reported; no data was drawn from VA medical or pharmacy records. Specifically, female Veterans were asked "Have you taken any prescription medications in the past 12 months? (yes/ no)," and then were asked about use of multiple different classes of medications. Veterans were asked about use of a number of potentially teratogenic medications, which included those most commonly used: benzodiazepines, statins, and antihypertensive medications. For example, Veterans were asked whether they had taken a "Benzodiazepine such as Diazepam (Valium), Lorazepam (Ativan), Clonazepam (Klonopin), or Alprazolam (Xanax)," or a "Statin such as Lovastatin (Mevacor). Simvastatin (Zocor), Atorvastatin (Lipitor), Pravastatin (Pravachol), Rosuvastatin (Crestor), or Fluvastatin (Lescol)." Similarly, Veterans were asked if they had "taken an angiotensin converting enzyme (ACE) inhibitor such as lisinopril (Zestril, Prinivil), Enalapril (Vasotec), Captopril (Capoten),"and/or “angiotensin receptor blockers (ARBs) such as losartan (Cozaar), Irbesartan (Avapro), Valsartan (Diovan)." Unfortunately, data was not collected on use of anti-epileptic medications, or other commonly used potentially teratogenic medications. Female Veterans were then asked, "when your healthcare provider prescribed the medications listed above, did he/she tell you if these medications had any chance of causing a birth defect? (yes/no)," and "How confident are you that your healthcare provider would tell you if a medication you are taking might cause a birth defect?" Response options included: very confident, moderately confident, neither confident nor unconfident, moderately unconfident, and very unconfident; we dichotomized these responses by considering Veterans to have felt "confident" in receipt of this counseling if they reported they were very confident, moderately confident, neither confident or unconfident, or "unconfident" if they reported feeling either moderately or very unconfident, in order to most conservatively estimate the number of women Veterans who lack confidence that they will receive desired counseling.

Details of women's reproductive health history were collected, including whether the Veteran was sexually active, had ever been pregnant, whether pregnancies had been planned, whether pregnancies resulted in abortion or birth, and whether any of the Veteran's children had been affected by birth defects. In addition, Veterans were asked, "Were any of the pregnancies the result of sexual assault or abuse while in the military? (yes/no)" Veterans were asked whether they had a history of infertility and whether they had used condoms with last sex. Veterans' recent use of hormonal contraception was self-reported; Veterans were 
asked, "During the past 12 months, have you taken prescription medicine for birth control?" In addition, Veterans were asked, "While in the military, did you ever have problems getting the birth control that you needed? (yes/no)."

Data were also collected on Veterans' sociodemographic characteristics, self-reported health history, including substance abuse, and health services use. Specifically, the survey asked whether the Veteran received healthcare from the VA only, non-VA providers only, or received both VA and non-VA care, and whether the veteran had received care from a VA women's health clinic. Veterans were asked whether they agreed or disagreed with the statement, "The VA has good, quality health care." Finally, Veterans were asked, "Do you plan to use the VA Healthcare system in the future?" and provided with the following response options: yes, as a primary source of care, as a back up to non-VA care, for prescriptions only, and no.

We tabulated responses to each of these questions and then used chi-square tests, or Fischer's exact tests when appropriate, to examine whether female Veterans' receipt of teratogenic risk counseling varied by the Veteran's sociodemographic characteristics, health history, or where the Veteran received healthcare. In addition, we examined whether receipt of such counseling was associated with Veterans' recent use of hormonal contraception. Finally, we examined the relationship between women's use of potentially teratogenic medications in the last year and their confidence that they would be counseled about teratogenic risks. All analyses were done using SAS version 9.1 (SAS Institute, Cary, NC); a priori, $p<0.05$ was considered statistically significant. The study was approved by the institutional review boards of the VA Connecticut and Yale University.

\section{RESULTS}

Of the 322 premenopausal female Veterans who completed surveys, $286(89 \%)$ female Veterans reported use of a prescription medication in the last 12 months. The mean age of these Veterans was 30.2 years; other sociodemographic characteristics of these Veterans are shown in Table 1. Most $(88 \%)$ of these female Veterans were sexually active. Less than half (48\%) of participating Veterans reported use of prescription contraception in the last 12 months (Table 2).

Only $24 \%$ of participating Veterans reported they had been told by a healthcare provider if their medications had any chance of causing birth defects. Receipt of teratogenic risk counseling by female Veterans was similar whether the Veteran received care within or outside the VA system, and whether the veteran had visited a VA women's clinic (Table 1). Receipt of counseling about risk of medication-
Table 1. Sociodemographic Characteristics of Participating Female Veterans, By Self-Reported Receipt of Counseling About Risk of Medication-Induced Birth Defects $\left(n=286^{\circ}\right)$

\begin{tabular}{|c|c|c|c|c|}
\hline & $\begin{array}{l}\text { Total } \\
\text { N (\%) }\end{array}$ & $\begin{array}{l}\text { Received } \\
\text { counseling }\end{array}$ & $\begin{array}{l}\text { No } \\
\text { counseling }\end{array}$ & p-value ${ }^{\dagger}$ \\
\hline Education & & & & 0.92 \\
\hline $\begin{array}{l}\text { High School diploma } \\
\text { or G.E.D. }\end{array}$ & $73(25)$ & $16(22)$ & $56(77)$ & \\
\hline $\begin{array}{l}\text { Some college or } \\
\text { Associates degree }\end{array}$ & $69(24)$ & $17(25)$ & $51(74)$ & \\
\hline College degree & $108(38)$ & $25(23)$ & $83(77)$ & \\
\hline $\begin{array}{l}\text { Graduate or } \\
\text { professional degree }\end{array}$ & $36(13)$ & $10(28)$ & $26(72)$ & \\
\hline Race/ethnicity & & & & 0.94 \\
\hline $\begin{array}{l}\text { White, not Hispanic/ } \\
\text { Latino }\end{array}$ & $239(84)$ & $56(23)$ & $182(76)$ & \\
\hline $\begin{array}{l}\text { Black, not Hispanic/ } \\
\text { Latino }\end{array}$ & $17(6)$ & $4(24)$ & $13(76)$ & \\
\hline Hispanic/Latino & $25(9)$ & $7(28)$ & $17(68)$ & \\
\hline $\begin{array}{l}\text { Asian or Pacific } \\
\text { Islander }\end{array}$ & $5(2)$ & $1(20)$ & $4(80)$ & \\
\hline Married & $116(41)$ & $32(28)$ & $83(72)$ & 0.41 \\
\hline Divorced & $55(19)$ & $15(27)$ & $40(73)$ & \\
\hline Separated & $5(2)$ & $1(20)$ & $4(80)$ & \\
\hline Widowed & $4(1)$ & $0(0)$ & $4(100)$ & \\
\hline Single & $106(37)$ & $20(19)$ & $85(80)$ & \\
\hline Living alone & $64(22)$ & $15(23)$ & $48(75)$ & 0.98 \\
\hline With husband & $106(48)$ & $27(25)$ & $78(74)$ & 0.78 \\
\hline $\begin{array}{l}\text { With male partner or } \\
\text { boyfriend }\end{array}$ & $30(14)$ & $5(17)$ & $25(83)$ & 0.78 \\
\hline Annual income (own) & & & & 0.33 \\
\hline$<\$ 25,000$ & $107(37)$ & $26(25)$ & $79(75)$ & \\
\hline$\$ 25,001-\$ 50,000$ & $92(32)$ & $15(16)$ & $77(84)$ & \\
\hline$\$ 50,001-\$ 75,000$ & $52(18)$ & $17(33)$ & $35(67)$ & \\
\hline$\$ 75,001-\$ 100,000$ & $25(9)$ & $8(32)$ & $17(68)$ & \\
\hline$\$ 100,001-\$ 150,000$ & $6(2)$ & $2(33)$ & $4(67)$ & \\
\hline Refused/Don’t know & $4(2)$ & $0(0)$ & $4(100)$ & \\
\hline $\begin{array}{l}\text { Current Private Health } \\
\text { Insurance }\end{array}$ & $160(56)$ & $36(23)$ & $124(78)$ & 0.52 \\
\hline Health Care from & & & & 0.42 \\
\hline $\begin{array}{l}\text { Only from VA } \\
\text { providers }\end{array}$ & $47(17)$ & $14(30)$ & $32(68)$ & \\
\hline $\begin{array}{l}\text { Only from non-VA } \\
\text { providers }\end{array}$ & $45(17)$ & $9(20)$ & $36(80)$ & \\
\hline $\begin{array}{l}\text { Both VA and non-VA } \\
\text { providers }\end{array}$ & $186(67)$ & $41(22)$ & $144(77)$ & \\
\hline $\begin{array}{l}\text { VA Women's Center } \\
\text { patient }\end{array}$ & $37(32)$ & 7 (19) & $30(81)$ & 0.43 \\
\hline
\end{tabular}

* We excluded from these analyses data from female veterans over 50 years of age, those who were using postmenopausal hormone therapy, and female veterans who had not used prescription medication in the last 12 months

'From chi-squared tests, or Fisher's exact tests for overall differences in receipt of counseling by groups

induced birth defects did not vary by education, race, marital status (Table 1), or reproductive history (Table 2). Women who used potentially teratogenic medications, such as an ACE-inhibitor or ARB, were not more likely to be warned about the risk of medication-induced birth defects, and in fact, tended to be less likely to receive such counseling, than women who used other medications (Table 3). Women who had been counseled about teratogenic risks tended to be more likely to use prescription contraception ( $56 \%$ vs $46 \%, p=0.16$ ), but this finding did not reach statistical significance.

The majority of female Veterans were confident that they would be told by their healthcare provider if a medication 
Table 2. Reproductive Characteristics of Participating Female Veterans, By Self-Reported Receipt of Counseling About Risk of Medication-Induced Birth Defects $\left(n=286^{*}\right)$

\begin{tabular}{|c|c|c|c|c|}
\hline & $\begin{array}{l}\text { Total } \\
\text { N (\%) }\end{array}$ & $\begin{array}{l}\text { Received } \\
\text { counseling } \\
\text { N }(\%)\end{array}$ & $\begin{array}{l}\text { No } \\
\text { counseling } \\
\text { N (\%) }\end{array}$ & p-value \\
\hline Sexually active & $245(86)$ & $62(25)$ & $183(74)$ & 0.15 \\
\hline Prior pregnancy & $173(63)$ & $44(25)$ & $129(75)$ & 0.27 \\
\hline $\begin{array}{l}\text { Unintended } \\
\text { pregnancy }\end{array}$ & $126(72)$ & $32(25)$ & $94(75)$ & 0.61 \\
\hline Prior abortion & $51(29)$ & $12(24)$ & $39(76)$ & 0.58 \\
\hline Prior birth & $114(66)$ & $30(26)$ & $84(74)$ & 0.96 \\
\hline Prior birth defect & $10(6)$ & $3(30)$ & $7(70)$ & 0.79 \\
\hline Infertility $^{\dagger}$ & $31(11)$ & $11(35)$ & $20(65)$ & 0.12 \\
\hline \multicolumn{5}{|l|}{ Used contraception } \\
\hline $\begin{array}{l}\text { Condom with last } \\
\text { sex }\end{array}$ & $61(22)$ & $9(15)$ & $52(85)$ & 0.06 \\
\hline $\begin{array}{l}\text { Hormonal method } \\
\text { in last } 12 \text { months }\end{array}$ & $136(48)$ & $38(28)$ & $98(72)$ & 0.16 \\
\hline
\end{tabular}

*We excluded from these analyses data from female veterans over 50 years of age, veterans using postmenopausal hormone therapy, or veterans who had not used a prescription medication in the last 12 months

'Infertility measured as ever tried to become pregnant for $>12$ months

${ }^{*}$ From chi-squared tests and Fisher's exact tests, when appropriate

they were prescribed might cause a birth defect (41\% very confident, $29 \%$ moderately confident, $19 \%$ neither confident/unconfident). Only $7 \%$ reported they were moderately unconfident, while $4 \%$ were very unconfident that they would be counseled about teratogenic risks. However, women who had recently used a medication labeled by the FDA as potentially teratogenic were less confident that they would be counseled about teratogenic risks (Table 3). For example, confidence that they would receive teratogenic risk counseling was lower among the four women who reported use of an ACE-inhibitor or ARB than among women who were not using one of these medications (50\% vs $90 \%, p=0.05)$.

Table 3. Self-Reported Receipt of Counseling about Risks of Medication-Induced Birth Defects and Confidence in Receiving Such Counseling

\begin{tabular}{lll}
\hline \hline & $\begin{array}{l}\text { Received } \\
\text { counseling }\end{array}$ & $\begin{array}{l}\text { Confident they } \\
\text { would receive } \\
\text { counseling }\end{array}$ \\
\hline $\begin{array}{l}\text { Any medication }(n=286) \\
\begin{array}{l}\text { Specific class D or X*medications: } \\
\text { Angiotensin converting enzyme } \\
\text { inhibitor or angiotensin receptor }\end{array}\end{array}$ & $24 \%$ & $90 \%$ \\
$\quad$ blocker $(n=4)$ & $0 \%$ & \\
Benzodiazepine $(n=37)$ & $22 \%$ & $80 \%$ \\
Statin $(n=16)$ & $19 \%$ & $81 \%$ \\
\hline
\end{tabular}

"The US Food and Drug Administration (FDA) labels medications using five categories. Class $A$ and $B$ medications are those for which there is no evidence of fetal harm in humans. Class $C$ designates drugs for which adequate studies are not available. Classes $D$ and $X$ are used to identify potentially teratogenic medications. Specifically, class $D$ medications are those for which there is evidence of fetal risk, but "the potential benefits from the use of the drug in pregnant women may be acceptable despite its potential risks; " class X medications are "contraindicated in women who are or may become pregnant"
Veterans' confidence that they would receive teratogenic risk counseling was not significantly associated with their sociodemographic characteristics. However, female Veterans were less likely to report confidence that they would receive teratogenic risk counseling if they had difficulty obtaining birth control while in the military (78\% vs $91 \%$, $p=0.04)$. Similarly, the $2.1 \%$ of female Veterans $(n=6)$ who reported they had become pregnant as the result of military sexual trauma were less confident they would receive such counseling ( $67 \%$ vs $91 \%, p=0.05$ ). Veterans were also less confident they would receive such counseling if they had a history of drug use (e.g. marijuana ( $75 \%$ vs $91 \%, p=0.02$ ), alcohol $(81 \%$ vs $91 \%, p=0.04)$, or "tranquilizers or 'nerve pills' such as benzodiazepines without a doctor's prescription" ( $71 \%$ vs $91 \%, p=0.006)$ ). In contrast, Veterans were more confident that they would be informed of teratogenic risks if they had previously had a pregnancy affected by birth defects.

Veterans who were confident that they would receive teratogenic risk counseling were more likely to agree with the statement that the "VA provides good quality healthcare," $p=0.04$, and to indicate that they planned to use the VA as a primary source of healthcare in the future ( $85 \%$ vs $94 \%, p=0.04)$.

\section{DISCUSSION}

We found that only a quarter of young female Veterans reported that their healthcare provider had warned them of teratogenic risks with medication use. This is concerning, as half the study participants reported no use of contraception, and thus may be at risk of unintended pregnancy. Given the relatively small size of this study, all associations identified should be viewed primarily as hypothesis-generating. However, as prior studies have found that half of female Veterans are dispensed potentially teratogenic medications, ${ }^{7}$ these findings indicate that need for ongoing efforts to ensure that female Veterans receive appropriate counseling when they are prescribed medications that can cause birth defects. Although the VA has only recently expanded its focus to include female Veterans, outside the VA this issue requires similar attention, as studies from multiple clinical settings have found that women of childbearing potentially are frequently prescribed potentially teratogenic medications. ${ }^{4,6,11,12}$

In order to help women optimize their health before pregnancy, comprehensive preconception counseling must include information about medication risks, alternative treatments that may be considered if pregnancy is desired, and effective methods of contraception if pregnancy is not desired. Unfortunately, many primary care physicians have limited knowledge of both teratogenic risks ${ }^{13}$ and rates of unintended pregnancy ${ }^{14}$; thus, ensuring that women receive teratogenic risk counseling may require ongoing clinician 
education. Currently, the VA is addressing this challenge by offering clinicians "mini-residencies" in Women's Health. Educational efforts modeled after those that have successfully encouraged clinicians to screen for depression ${ }^{15,16}$ may also be useful. Clinical decision support has been proposed as a way to alert clinicians to the need for teratogenic risk counseling, ${ }^{17}$ but refinement and evaluation of such decision support systems remain needed. Involving pharmacists in efforts to notify women about medication risks may also be of benefit. However, prior efforts to use laboratory and ultrasound data to alert dispensing pharmacists to pregnancies had unacceptably high rates of misidentification of ongoing pregnancy. ${ }^{18}$ In addition, women have indicated that they prefer to discuss plans for pregnancy with their primary care provider in the privacy of the clinic, rather than in pharmacy settings. ${ }^{19}$ Thus, if pharmacists are to be involved in providing reproductive health counseling, attention must be given to ensuring patient privacy for discussions in pharmacies or other clinical settings.

Although the large majority of female Veterans trusted that their health care providers would provide them with information about teratogenic risks, Veterans who had received medications that were labeled as potentially teratogenic, such as ACE-I and ARB, without discussing these risks with their prescribing clinician had less confidence in their healthcare providers. Similarly, women who had ever had difficulties accessing desired services (e.g., contraception) in the military were less likely to trust they would receive counseling about teratogenic risks.

Patients' trust in their healthcare providers is important for many reasons. ${ }^{20-23}$ For example, trust in healthcare providers has been associated with adherence to therapeutic regimens, ${ }^{24}$ receipt of needed services, ${ }^{25}$ and health outcomes. ${ }^{26}$ Thus, appropriately alerting female patients to teratogenic risks can be seen as part of the larger mission of earning our patients trust in order to effectively work with them to improve health outcomes.

Limitations of this study include the relatively small sample size and limited response rate. We conducted multiple comparisons, which may increase the chance of type 1 error; thus, none of our findings should be considered definitive, but rather as hypothesis-generating. We have no information on the ways Veterans who responded to this survey may differ from those who did not; however, this study population was more educated, and included fewer Black Veterans than nationally representative samples, which are $30 \%$ Black. $^{7}$ As WVCS did not ask women about their use of all potentially teratogenic medications, it is not possible to estimate whether women in this sample were more or less likely to use potentially teratogenic medications than the average female Veteran. In addition, we have no data on the quality, timing or content of the counseling Veterans received about risks of medication-induced birth defects. Veterans' responses to the question about how confident they were that they would receive teratogenic risk counseling when needed may have been affected by the survey's first asking whether women had received such counseling.

Nonetheless, relatively few women Veterans reported they had been told their medications had any chance of causing a birth defect. Thus, these findings support other recent work ${ }^{17}$ in indicating that efforts remain needed to ensure that all women receive appropriate counseling when medications that can cause birth defects are prescribed. Recent changes in VA women's healthcare, such as the implementation of comprehensive primary care to eliminate fragmentation and gaps in women Veterans' care, efforts to educate VA primary care providers in basic women's health, including preconception care, through Women's Health Mini-Residencies, development of a preconception care template, and multiple educational conferences have all been designed to ensure the VA provides women Veterans the best possible care. Private sector health care providers should join VA providers in striving to meet these new national standards for provision of comprehensive Women's Health care.

Acknowledgements: This work was supported by VA HSR\&D grant \#DHI 07-065.

Conflict of Interest: The authors declare that they do not have a conflict of interest.

Corresponding Author: Eleanor Bimla Schwarz, MD, MS; Department of Medicine,

University of Pittsburgh, 230 McKee Place, Suite 600, Pittsburgh, PA 15213, USA (e-mail: schwarzeb@upmc.edu).

\section{REFERENCES}

1. Mathews TJ, MacDorman MF. Infant mortality statistics from the 2006 period linked birth/infant death data set. Natl Vital Stat Rep. 2010;58 (17): 1-31. Epub 2010/09/08.

2. Centers for Disease Control and Prevention. Update on overall prevalence of major birth defects-Atlanta, Georgia, 1978-2005. MMWR Morb Mortal Wkly Rep. 2008;57(1):1-5. Epub 2008/01/11.

3. Centers for Disease Control and Prevention. Hospital stays, hospital charges, and in-hospital deaths among infants with selected birth defects-United States, 2003. MMWR Morb Mortal Wkly Rep. 2007;56 (2):25-9. Epub 2007/01/19.

4. Schwarz EB, Maselli J, Norton M, Gonzales R. Prescription of teratogenic medications in United States ambulatory practices. Am J Med. 2005;118(11):1240-9. Epub 2005/11/08.

5. National Center for Veterans Analysis and Statistics. Veteran Population. 2007 [cited 2009 November 2]; Available from: http://wwwl.va.gov/ vetdata/page.cfm?pg=15.

6. Schwarz EB, Postlethwaite DA, Hung YY, Armstrong MA. Documentation of contraception and pregnancy when prescribing potentially teratogenic medications for reproductive-age women. Ann Intern Med. 2007;147(6):370-6. Epub 2007/09/19.

7. Schwarz EB, Longo LS, Zhao X, Stone RA, Cunningham F, Good CB. Provision of potentially teratogenic medications to female veterans of childbearing age. Med Care. 2010;48(9):834-42. Epub 2010/08/14.

8. Andrade SE, Gurwitz JH, Davis RL, Chan KA, Finkelstein JA, Fortman K, et al. Prescription drug use in pregnancy. Am J Obstet Gynecol. 2004;191(2):398-407. 
9. Lee E, Maneno MK, Smith L, Weiss SR, Zuckerman IH, Wutoh AK, et al. National patterns of medication use during pregnancy. Pharmacoepidemiol Drug Saf. 2006;15(8):537-45.

10. Haskell SG, Mattocks K, Goulet JL, Krebs EE, Skanderson M, Leslie D, et al. The burden of illness in the first year home: do male and female VA users differ in health conditions and healthcare utilization. Womens Health Issues. 2011;21(1):92-7. Epub 2010/12/28.

11. Fritsche MD, Ables AZ, Bendyk H. Opportunities missed: improving the rate of contraceptive counseling or provision when prescribing reproductive-aged women potentially teratogenic medications in a family medicine resident clinic. Contraception. 2011;84(4):372-6. Epub 2011/09/17.

12. Morrical-Kline KA, Walton AM, Guildenbecher TM. Teratogen use in women of childbearing potential: an intervention study. J Am Board Fam Med. 2011;24(3):262-71. Epub 2011/05/10.

13. Eisenberg DL, Stika C, Desai A, Baker D, Yost KJ. Providing contraception for women taking potentially teratogenic medications: a survey of internal medicine physicians' knowledge, attitudes and barriers. J Gen Intern Med. 2010;25(4):291-7. Epub 2010/01/21.

14. Parisi SM, Zikovich S, Chuang $\mathbf{C H}$, Sobota M, Nothnagle M, Schwarz EB. Primary care physicians' perceptions of rates of unintended pregnancy. Contraception 2012;86(1):48-54.

15. Freed RD, Chan PT, Boger KD, Tompson MC. Enhancing maternal depression recognition in health care settings: a review of strategies to improve detection, reduce barriers, and reach mothers in need. Fam Syst Health. 2012;30(1):1-18. Epub 2012/03/21.

16. Yawn BP, Dietrich AJ, Wollan P, Bertram S, Graham D, Huff J, et al. TRIPPD: a practice-based network effectiveness study of postpartum depression screening and management. Ann Fam Med. 2012;10(4):320 9. Epub 2012/07/11

17. Schwarz EB, Parisi SM, Handler SM, Koren G, Cohen ED, Shevchik GJ, et al. Clinical Decision Support to Promote Safe Prescribing to
Women of Reproductive Age: A Cluster-Randomized Trial. J Gen Intern Med. 2012;27(7):831-8.

18. Raebel MA, Carroll NM, Kelleher JA, Chester EA, Berga S, Magid DJ. Randomized trial to improve prescribing safety during pregnancy. J Am Med Inform Assoc. 2007;14(4):440-50. Epub 2007/04/27.

19. Santucci AK, Gold MA, Akers AY, Borrero S, Schwarz EB. Women's perspectives on counseling about risks for medication-induced birth defects. Birth Defects Res A Clin Mol Teratol. 2010;88(1):64-9. Epub 2009/07/29.

20. Shenolikar RA, Balkrishnan R, Hall MA. How patient-physician encounters in critical medical situations affect trust: results of a national survey. BMC Heal Serv Res. 2004;4(1):24. Epub 2004/09/09.

21. Stepanikova I, Mollborn S, Cook KS, Thom DH, Kramer RM. Patients race, ethnicity, language, and trust in a physician. J Health Soc Behav. 2006;47(4):390-405. Epub 2007/01/24.

22. Thom DH, Hall MA, Pawlson LG. Measuring patients' trust in physicians when assessing quality of care. Health Aff (Millwood). 2004;23 (4): 124-32. Epub 2004/08/21.

23. Lee JS, Tamayo-Sarver J, Kinneer P, Hobgood C. Association between patient race/ethnicity and perceived interpersonal aspects of care in the emergency department. J Natl Med Assoc. 2008;100(1):79-85. Epub 2008/02/19

24. Altice FL, Mostashari F, Friedland GH. Trust and the acceptance of and adherence to antiretroviral therapy. J Acquir Immune Defic Syndr. 2001;28(1):47-58. Epub 2001/10/02.

25. Thom DH, Kravitz RL, Bell RA, Krupat E, Azari R. Patient trust in the physician: relationship to patient requests. Fam Pract. 2002;19(5):47683. Epub 2002/10/03.

26. Safran DG, Taira DA, Rogers WH, Kosinski M, Ware JE, Tarlov AR. Linking primary care performance to outcomes of care. J Fam Pract. 1998;47(3):213-20. Epub 1998/09/30. 